\title{
Preliminary Evaluation of the Silica and Others Chemical Constituents of the Lyophilized Tea of Equisetum Arvense and Application of Its Biomass Wastes for Copper Adsorption
}

\author{
Camila Muraroto Monteiro ${ }^{1}$, Priscila Fernanda Pereira Barbosa ${ }^{1}$, Denys Ribeiro de Oliveira ${ }^{1}$, Leonardo Lataro Paim ${ }^{2}$, \\ Ana Paula Rizzato Nakamura ${ }^{1}$, Devaney Ribeiro do Carmo ${ }^{1}$ \\ ${ }^{1}$ São Paulo State University (Unesp), School of Natural Sciences and Engineering, Department of Physics and \\ Chemistry, Ilha Solteira, Brazil \\ ${ }^{2}$ São Paulo State University (Unesp), Energy Engineering, Campus of Rosana, Brazil \\ Correspondence: Devaney Ribeiro do Carmo, São Paulo State University (Unesp), School of Natural Sciences and \\ Engineering, Department of Physics and Chemistry, Ilha Solteira, Brazil. E-mail: devaneydocarmo@ hotmail.com
}

Received: June 11, 2018 Accepted: July 15, 2018 Online Published: July 26, 2018

doi:10.5539/ijc.v10n3p87 URL: https://doi.org/10.5539/ijc.v10n3p87

\begin{abstract}
The herb Equisetum arvense is an herbaceous plant, commonly known as horsetail and as a medicinal plant. Its therapeutic resource is diffused intensely in the urban environment as an alternative or complementary form to allopathic medicines, therefore it is an important theme focused on medicine and popular health. In this context, the focus of the present work was to characterize the product of the tea from a manipulation form made by specialized pharmacy (M) and other natural product banking (B). The two horsetails were extracted in aqueous medium since this is the form in which the material is absorbed by the organisms. The $\mathrm{M}$ and $\mathrm{B}$ lyophilized products were preliminary characterized by infrared spectroscopy (FTIR), visible ultraviolet (Uv-vis), scanning electron microscopy (SEM) and X-ray dispersive energy (EDX). The resulting biomass adsorption (wastes) were applied in the cupric ions adsorption and the maximum adsorption capacity ( $\mathrm{Nf}^{\max }$ of $\mathrm{M}$ and $\mathrm{B}$ horsetail were $4.4 \times 10^{-4} \mathrm{~mol} \mathrm{~g}^{-1}$ and $2.6 \times 10^{-4} \mathrm{~mol} \mathrm{~g}^{-1}$ respectively.
\end{abstract}

Keywords: equisetum arvense, horsetail, lyophylization, chararacterization, adsorption

\section{Introduction}

The herb Equisetum arvense is an herbaceous plant of Equisetopsida class, Equisetales order, Equisetaceae family and belonging to pteridófitas group, commonly known as horsetail. It is originated in Europe, which has in its composition: minerals, potassium, magnesium, aluminum, calcium, phosphorus, phosphorus and sodium besides it is also known as one of the plants with the highest accumulation of silica (biogenic silica) (Sola-Rabada et al., 2016). The horsetail usually has more than $10 \%$ of inorganic constituents (Mimica-Dukic et al., 2008) phenolic compounds, flavonoids, among others (Hodson et al., 2005).

The horsetail is a ground plant with the largest amount of silica, which allows it has several applications in medicine area (Des Marais et al., 2003). Researchers believe that the anti-bacterial and antiseptic medicinal properties associated with the plant are due to the high silica content. But the way how silica is found in tea can determine its property and use (Holzhuter et al., 2003; Ma et al., 2006).

The silica is deposited on plant stems in the form of a thin surface layer. Silicon in orthosilicic acid form [Si $\left(\mathrm{OH}_{4}\right]$ is absorbed by the plant and deposited on the amorphous form, remaining immobile and it is not redistributed (Ferraz et al., 2008; Vivancos et al., 2016)).

The horsetail is widely used in folk medicine to fight against tuberculosis (Di Giorgio et al., 2015) lung problems, internal bleeding, urine retention (night urinary incontinence of children and elderly), prostate problems, osteoporosis, gastric ulcers, loss of blood from nose, mouth and the rectum and for cellulite treatment (Franco \& Fontana, 1997; Gürbüz \&Yesilada, 2008) In addition to these applications, it can also be used as a diuretic, for controlling cholesterol and for treating senile skin. It is used in Europe as an abrasive and metal polisher due to the presence of silica (Dos Santos, et al 2005; Husby, 2013; Mitani \& Ma, 2015).

Currently, the use of the horsetail as a medicinal plant is a therapeutic resource diffused intensely in the urban environment, as an alternative or complementary form to allopathic medicines, therefore it is an important theme 
focused on medicine and popular health.

Phytochemical analyzes of $E$. arvense hydroalcoholic extracts revealed the presence of flavonoids (isoquercetin, camphorol), sterols ( $\beta$-sitosterol, campesterol, isofucoterol), tannins, saponins and alkaloids (equispermine, palustine) (Ferraz et al., 2008; Cramer et al., 2005), these compounds are potential adsorbents and / or transition metal complexing agents. The adsorption is one of natural processes that results in immobilization and accumulation of a metallic ion, contained in a certain liquid, which fixes on a static solid surface the adsorbent (Datta et al., 2013). The adsorption process can be used to reduce the concentration of pollutant species when they are at levels above that are allowed to humans (Da Silveira et al., 2018).

The complete adsorption process can be described quantitatively by adsorption isotherms, which in constant temperature provides data related to adsorbed amount (Nf) and solute concentration (C) after the equilibrium be established (Da Silveira et al., 2018).

The focus of the present work was to characterize the product of the tea whose was extracted in aqueous medium (Since this is the form in which the material is absorbed by the organisms) by infrared spectroscopy (FTIR), visible ultraviolet (Uv-vis), scanning electron microscopy (SEM) and X-ray dispersive energy (EDX). In addition to carry out a study of its biomass adsorption (wastes) in aqueous medium with cupric ions $\left(\mathrm{Cu}^{2+}\right)$, thus determining its adsorptive capacity. Emphasis was placed on the presence of metals, mainly Si

\section{Material and Methods}

\subsection{Reagents}

All reagents were obtained from Merck. All solutions were prepared with deionized water from the Milli-Q system from Millipore at a resistivity no less than $18.2 \mathrm{M} \Omega \mathrm{cm}^{-1}$ at $25^{\circ} \mathrm{C}$.

\subsection{Material}

The study was carried out with two types of horsetail teas purchased commercially in different establishments. The Horsetails were obtained in a natural product banking (B) and manipulated by specialized pharmacy (M). The sample $\mathrm{M}$ was manipulated using only leaves from the plant (as informed by the establishment) and it had extremely fine texture (powder) while the sample (B) has a coarser texture with visible parts of the plant and it was made with the leaves (bracts) and also the stalks of the horsetail.

\subsection{Experimental Procedure}

Initially B was transformed into powder using a knife mill (TECNAL-TE650 series 97003) with a 1.0mm porosity aluminum sieve. The tea (both $\mathrm{B}$ and $\mathrm{M}$ ) was prepared by adding $25 \mathrm{~g}$ of the material in a beaker containing $350 \mathrm{ml}$ of deionized water, kept under mechanical stirring for 7 hours, on a heating plate with a constant temperature of $50{ }^{\circ} \mathrm{C}$, with periodic monitoring of the process (Figure 1). The $\mathrm{pH}$ of all solutions was approximately 6.5 at the beginning of the process and remained at this value until the end.

After tea preparation, a 5-micron porosity sintered plate filter was used to separate the solid and liquid phases by vacuum filtration (Figure 2). The filtered liquid (extract) was transferred to smaller vials (filled with the liquid until its half) (Figure 3A). The vials were sealed with pieces of cotton and parafilm paper and then several small needle holes were made on the surface. The extract was frozen at $-10^{\circ} \mathrm{C}$ for $36 \mathrm{~h}$ and was transferred to a campanula and lyophilized for $24 \mathrm{~h}$ which was employed a TERRONI LB1500TT lyophilizer. The lyophilized product was stored (Figure 3B) in a vacuum desiccator to prevent that the dried material would absorb water, as the horsetail is highly hygroscopic. The solid phase formed in all the processes was oven dried at $100^{\circ} \mathrm{C}$ and stored in a dry flask to be used in the adsorption study.

\subsection{Techniques}

\subsubsection{Infrared Region Spectroscopy (FTIR)}

A Nicolet 5DXB FT-IR spectrophotometer (Nicolet Instrument, Madison, Wi) was used for the analysis of infrared spectroscopy of the lyophilized samples. A scanning for each sample at a resolution of $\pm 4 \mathrm{~cm}^{-1}$, in the range of 4000 to $400 \mathrm{~cm}^{-1}$, was employed.

\subsubsection{Uv-Vis (Visible Ultraviolet Spectroscopy)}

All samples were analyzed using Guided Wave spectrophotometry, model 260, equipped with tungsten-halogen lamp, silicon $(200$ to $1000 \mathrm{~nm})$ and germanium $(800$ to $2500 \mathrm{~nm})$ detectors.

\subsubsection{EDX (Dispersive Energy Spectroscopy) and SEM (Scanning Electron Microscopy)}


EDX and MEV were obtained by an electronic microscope of Jeol JTSM T-330 brand with EDX attached. Topological and qualitative analyzes of chemical constituents before (M1 and B1) and after the extraction (M and B lyophilized) as well as the wastes (residues) of the extracts filtration (denominated here B2 and M2) were carried out. The samples were mounted on metal support and placed into the electron microscope sample chamber. In this way, the elements content in the lyophilized extract and solid wastes were qualitatively determined by EDX.

\subsection{Adsorption}

The adsorption study was performed by batching technique with thermostatic flasks, using as adsorbent $50 \mathrm{mg}$ of the solid phase obtained after the B and $\mathrm{M}$ horsetail tea extraction.

For time study, $50 \mathrm{mg}$ of samples were placed with the $5.0 \times 10^{-3} \mathrm{~mol} \mathrm{~L}^{-1}$ standard solution of $\mathrm{CuCl}_{2} 5 \mathrm{H}_{2} \mathrm{O}$ in the thermostatic bottles. The system was submitted to magnetic stirring for predetermined time intervals $(10,20,30,40,50$, $60,70,80$ e 90 minutes) at controlled temperature $\left(25 \pm 1^{\circ}\right)$. After stirring time, the samples were resting for 10 minutes and then $10 \mathrm{~mL}$ aliquots were taken from each sample and carefully filtered on quantitative filter.

For concentration study, the same method was used, where $50 \mathrm{mg}$ of each horsetails that were mixed with $\mathrm{Cu}^{2+}$ metal cations in a solution which was previously diluted, but this time in different concentrations of the standard aliquots solution $(2.5,5.0,7.5,10,12.5,15,20,25$ and $30 \mathrm{~mL})$. This system was also kept under stirring for a determined time in the previous study (70 minutes) and after that time the filtration and separation of the aliquots were repeated for atomic absorption spectrophotometry.

The cupric ions concentration at equilibrium was determined in triplicate $(n=3)$ by concentration difference using an atomic absorption spectrophotometer (FAAS) of Varian Model 55B Spectra brand.

$\mathrm{Nf}$ (amount of adsorbed metal) in each sample was determined by the equation: $\mathrm{Nf}=(\mathrm{Na}-\mathrm{Ns}) / \mathrm{m}$, where $\mathrm{m}$ is the mass $(\mathrm{g})$ of adsorbent and $\mathrm{Na}$ and $\mathrm{Ns}$ are the initial and final concentrations of metal ions, respectively.

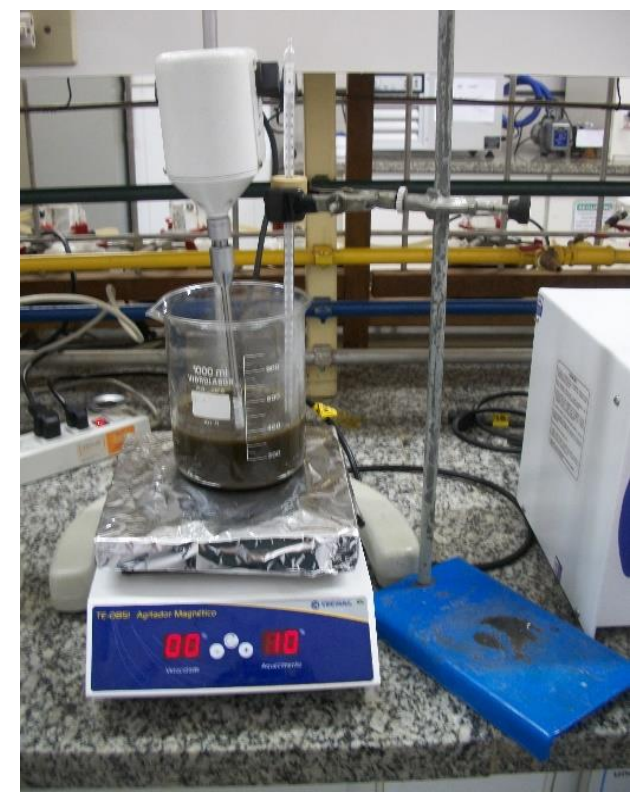

Figure 1. Horsetail tea preparation 


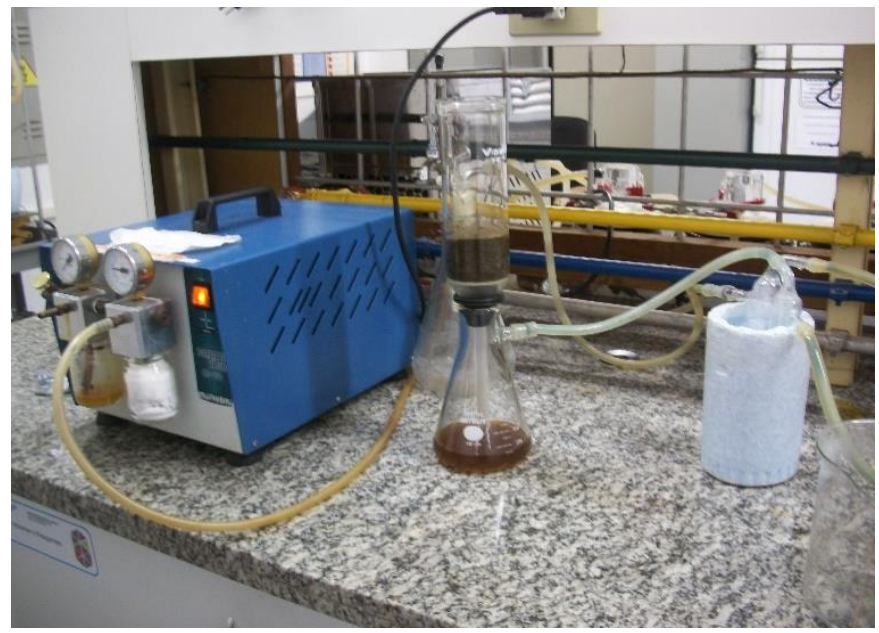

Figure 2. Tea filtration by vacuum filtration process

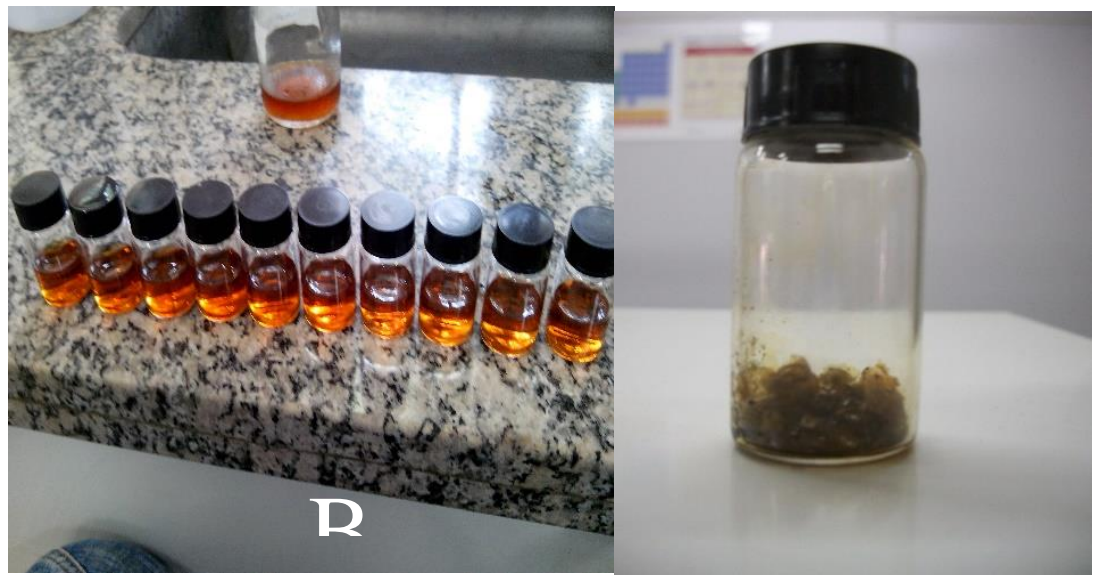

Figure 3. A. Extract filtered placed in vials for lyophilization process. B: Lyophilized extract

\section{Results and Discussion}

Through infrared spectroscopy, organic constituents' presence was observed in both materials (Figure 4). The horsetail presented typical absorption band of Silicon (vSi-O-S) in $1100 \mathrm{~cm}^{-1}$, proving its existence. Absorption bands near 3500 $\mathrm{cm}^{-1}$ and between $1600 \mathrm{~cm}^{-1}$ and $1000 \mathrm{~cm}^{-1}$ indicate the presence of aromatic rings, possibly due to the presence of flavonoids; the band at $2500 \mathrm{~cm}^{-1}$ is typical of carboxylic acid $(\mathrm{O}-\mathrm{H})$; bands between $3500 \mathrm{~cm}^{-1}$ and $3070 \mathrm{~cm}^{-1}$ are characteristic of amides (N-H) (Lopes \& Fascio, 2003). Therefore, some soluble compounds based on Silicon, Si $(\mathrm{OH})_{4}$ or $\mathrm{Si}(\mathrm{OH})_{3}$, which are present in the stalks of the herb (Holzhuter, et al., 2003) are also present in the extract. 


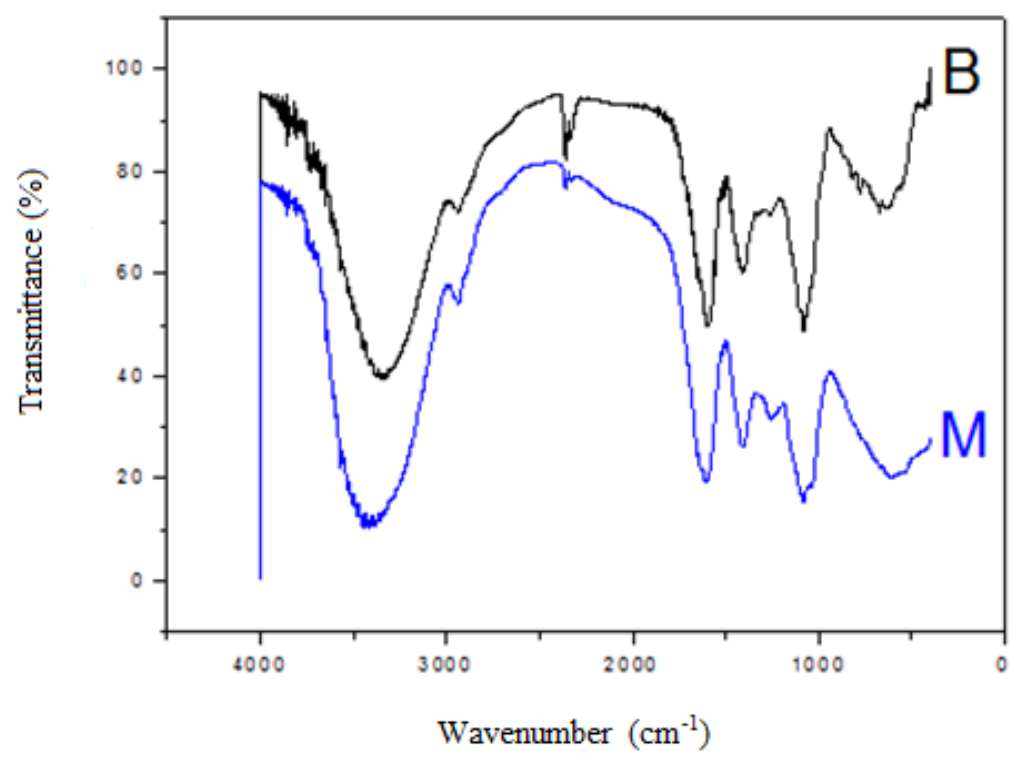

Figure 4. B and M Horsetail Spectra

Figures 5 and 6 illustrate the Uv-Vis spectra for both lyophilized horsetail samples where a band at 267 and $305 \mathrm{~nm}$ for B (Figure 6) can be observed after spectral deconvolution. For M (Figure 6) two bands located at 261 and $286 \mathrm{~nm}$ were also observed, all possibly related to apigenin presence (Francescato, 2013).

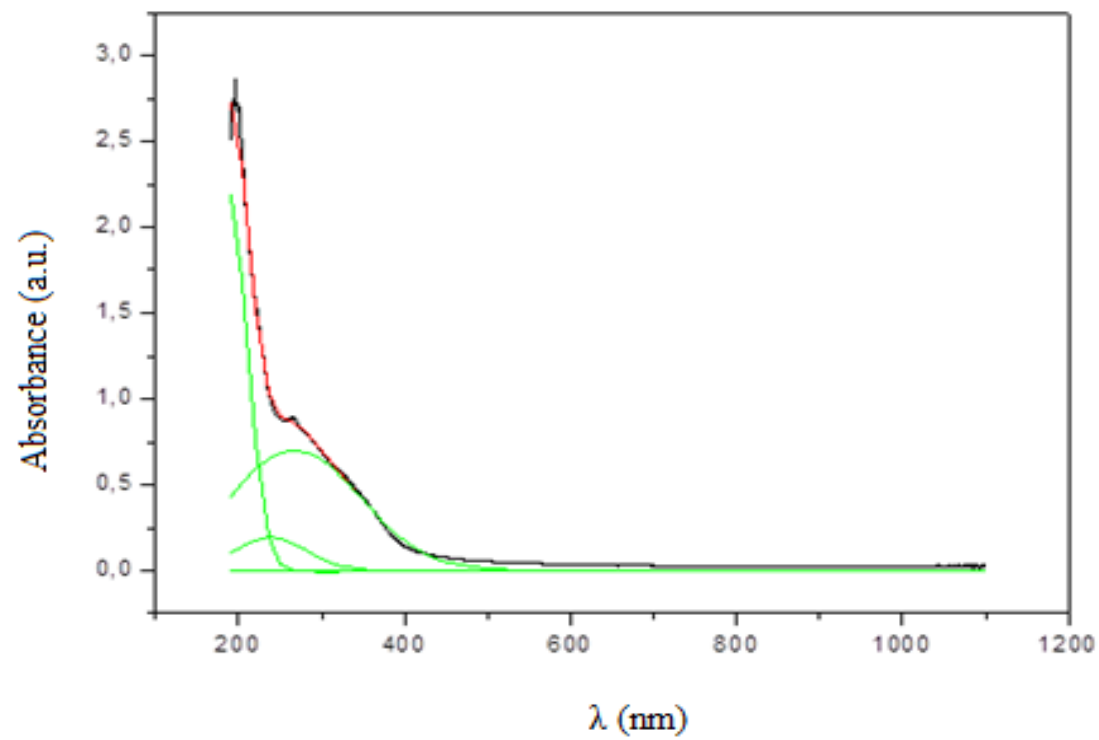

Figure 5. Electronic Spectrum with B sample deconvolution (Uv-Vis) 


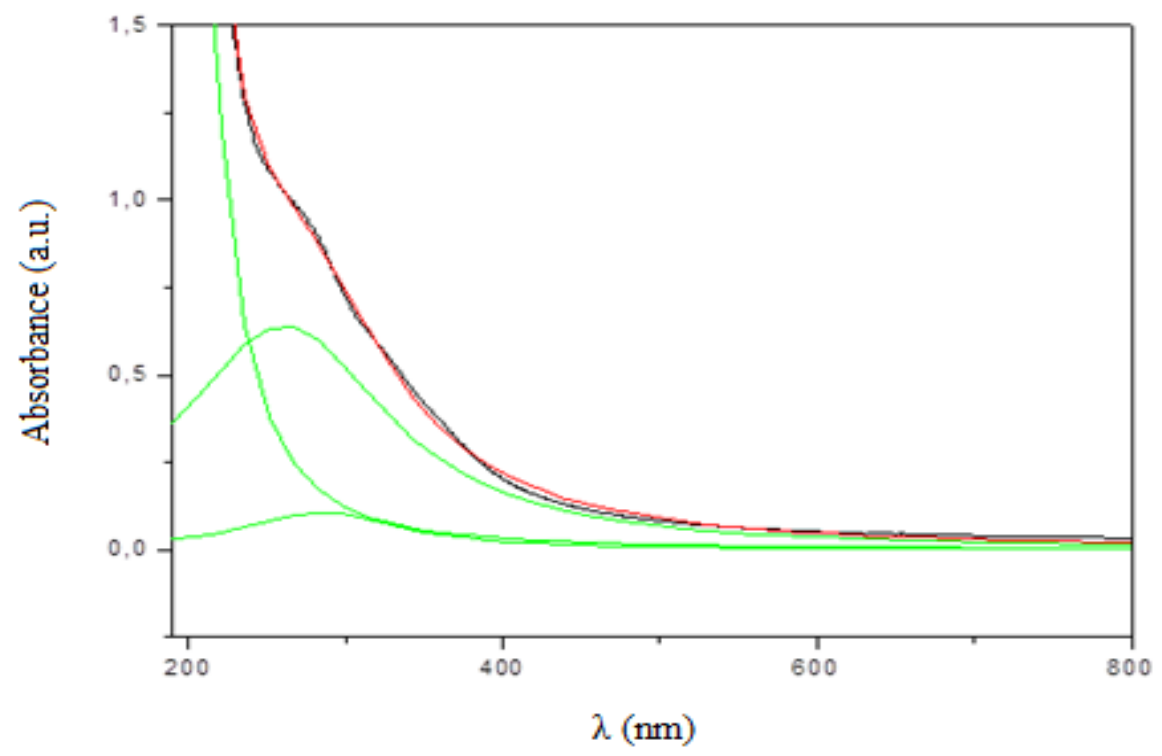

Figure 6. Electronic Spectrum with M sample deconvolution (Uv-Vis)

The great absorption capacity of the horsetail root gives it great diversity in the chemical constitution, which can be observed through the EDX. Both samples, B and M, presented the same chemical components and their approximate percentages. Aluminum was found in small percentage only in lyophilized sample M (Figure 7). The components found in the EDX analyzes are listed in Table 1.

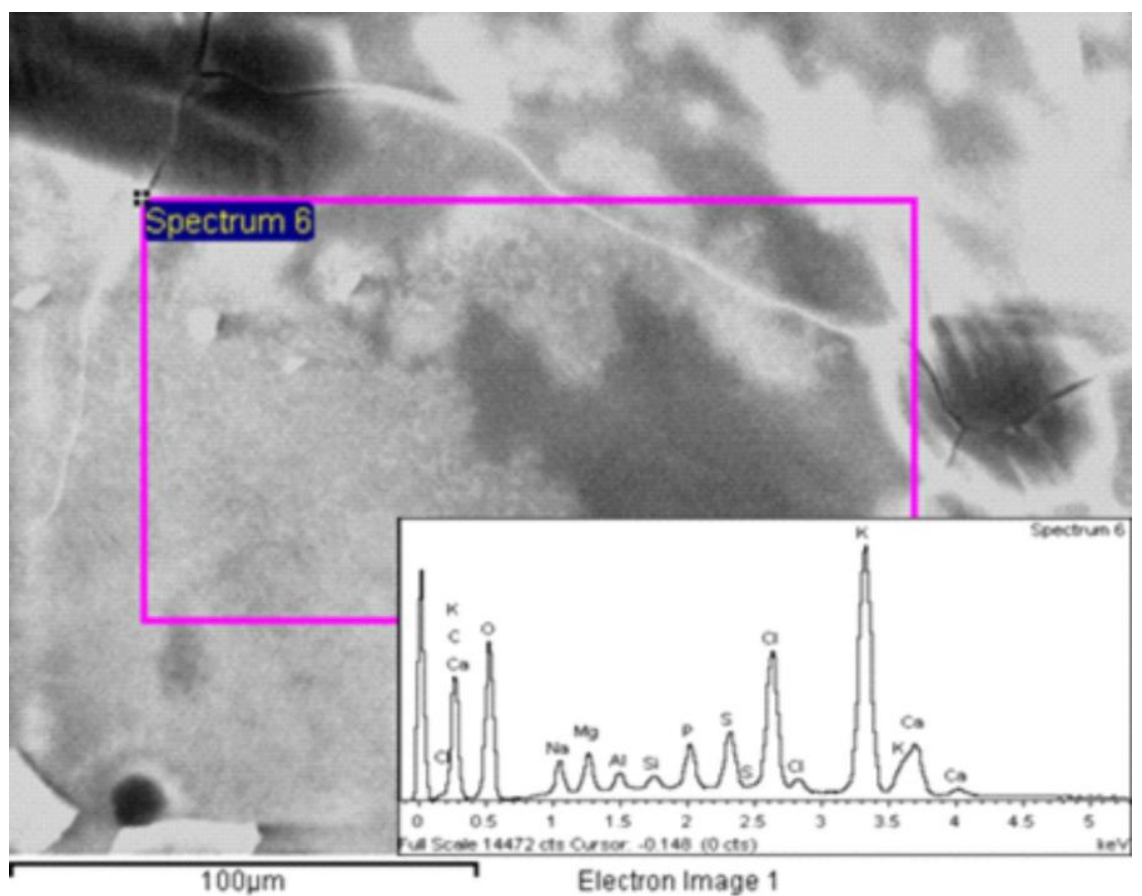

Figure 7. EDX analysis from lyophilized extract of M horsetail 
Table 1. EDX analysis of teas (B1 and M1), lyophilized extracts (B and M) and wastes (residues) from tea extracts (B2 and M2)

\begin{tabular}{ccccccc}
\hline Element & $\% \mathrm{~B}$ & $\% \mathrm{~B} 1$ & $\% \mathrm{~B} 2$ & $\% \mathrm{M}$ & $\% \mathrm{M} 1$ & $\% \mathrm{M} 2$ \\
\hline $\mathrm{C} \mathrm{K}$ & 34.22 & 42.89 & 39.27 & 30.88 & 43.08 & 45.30 \\
$\mathrm{O} \mathrm{K}$ & 50.46 & 47.81 & 38.70 & 39.76 & 44.48 & 48.45 \\
$\mathrm{Na} \mathrm{K}$ & 0.13 & - & - & 1.69 & 0.17 & 0.11 \\
$\mathrm{Mg} \mathrm{K}$ & 1.56 & 0.33 & 0.16 & 1.41 & 0.15 & 0.20 \\
$\mathrm{Al} \mathrm{K}$ & - & - & - & 0.51 & - & 0.16 \\
$\mathrm{Si} \mathrm{K}$ & 0.43 & 2.94 & 18.57 & 0.40 & 8.81 & 2.66 \\
$\mathrm{P} \mathrm{K}$ & 1.16 & 0.14 & - & 1.65 & 0.11 & - \\
$\mathrm{S} \mathrm{K}$ & 0.66 & 0.14 & 0.09 & 2.13 & 0.19 & 0.28 \\
$\mathrm{Cl} \mathrm{K}$ & 2.29 & 0.34 & 0.10 & 5.92 & 0.54 & 0.17 \\
$\mathrm{~K} \mathrm{~K}$ & 7.07 & 4.40 & 1.07 & 12.72 & 1.18 & 0.86 \\
$\mathrm{Ca} \mathrm{K}$ & 1.88 & 1.00 & 1.42 & 2.93 & 1.03 & 1.71 \\
$\mathrm{Mn} \mathrm{K}$ & 0.13 & - & - & - & - & - \\
$\mathrm{Fe} \mathrm{K}$ & - & - & 0.63 & - & 0.26 & 0.11 \\
\hline
\end{tabular}

According to qualitative levels listed in Table 1, carbon and oxygen are the components present in a higher percentage in both samples, being present $70 \%$ of the samples. Therefore, organic compounds are predominant in the chemical composition of the herb Equisetum arvense, while inorganic compounds make up only about $30 \%$ of the same.

The main constituents found in larger amounts in Equisetum arvense are $\mathrm{Mg}, \mathrm{Si}$, and $\mathrm{Ca}$. In addition to $\mathrm{Si}$ and $\mathrm{Mg}$, presence of $\mathrm{S}$ was also observed, but aluminum and fluorine presence were not observed, as described in the literature (Hodson et al., 2005).

By scanning electron microscopy (SEM) shown by Figures from 8 to 13 for different samples. In some of them can clearly observe microparticles of approximately 0.22 microns, attributed to the superficial layer of silica, generally found in the leaf and stem, and this dimension is very close to that described in the literature (Holzhuter et al., 2003)

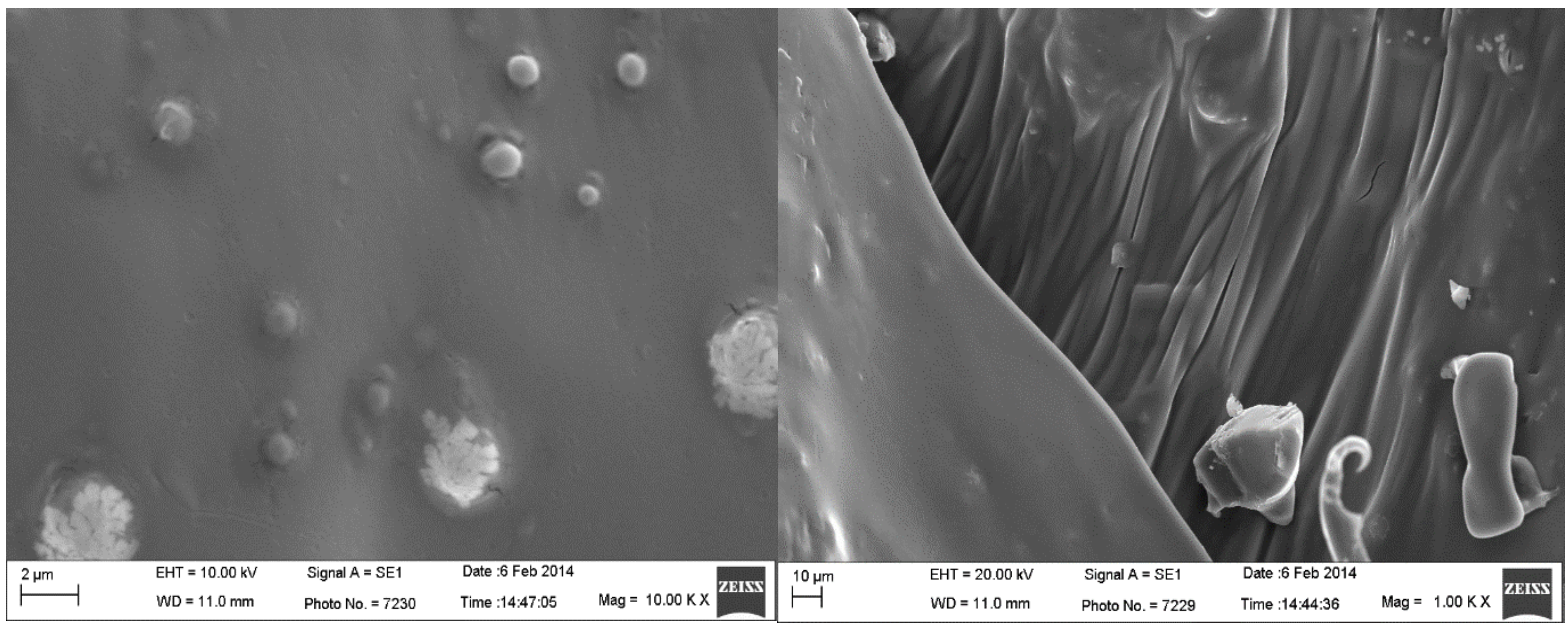

Figure 8. MEV of B horsetail sample 


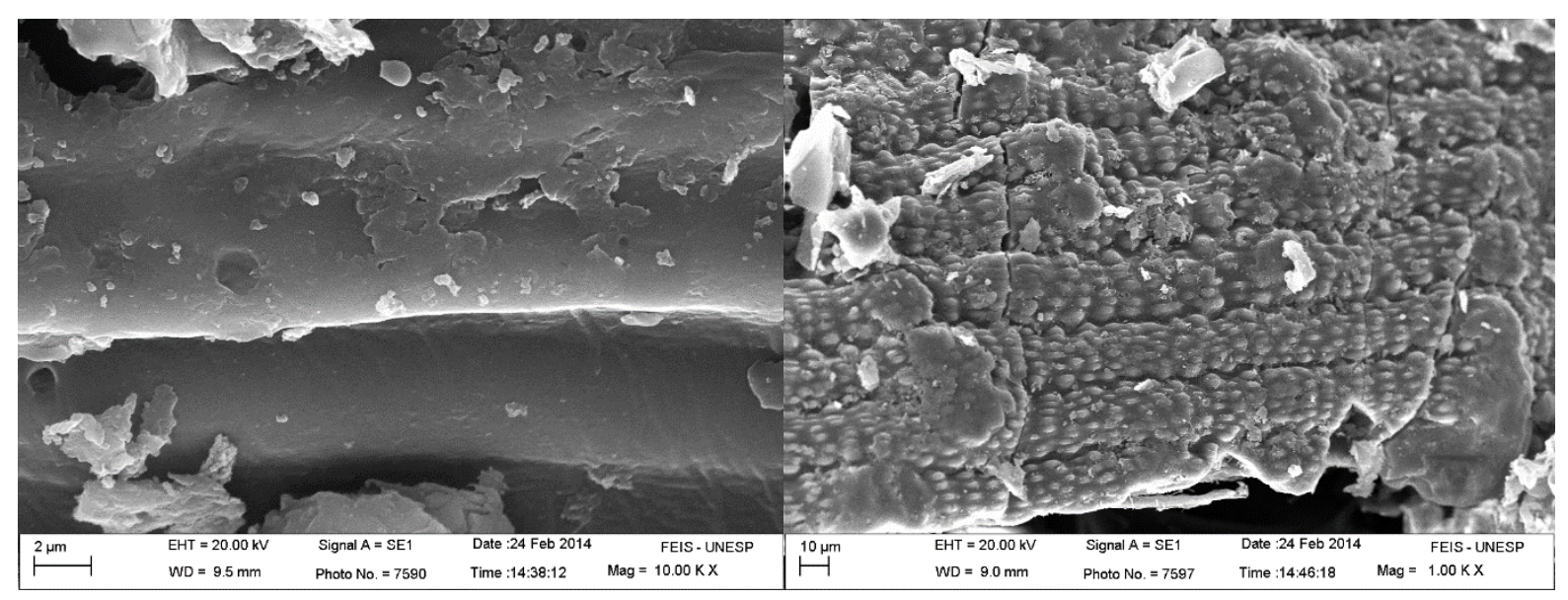

Figure 9. MEV of B1 horsetail sample

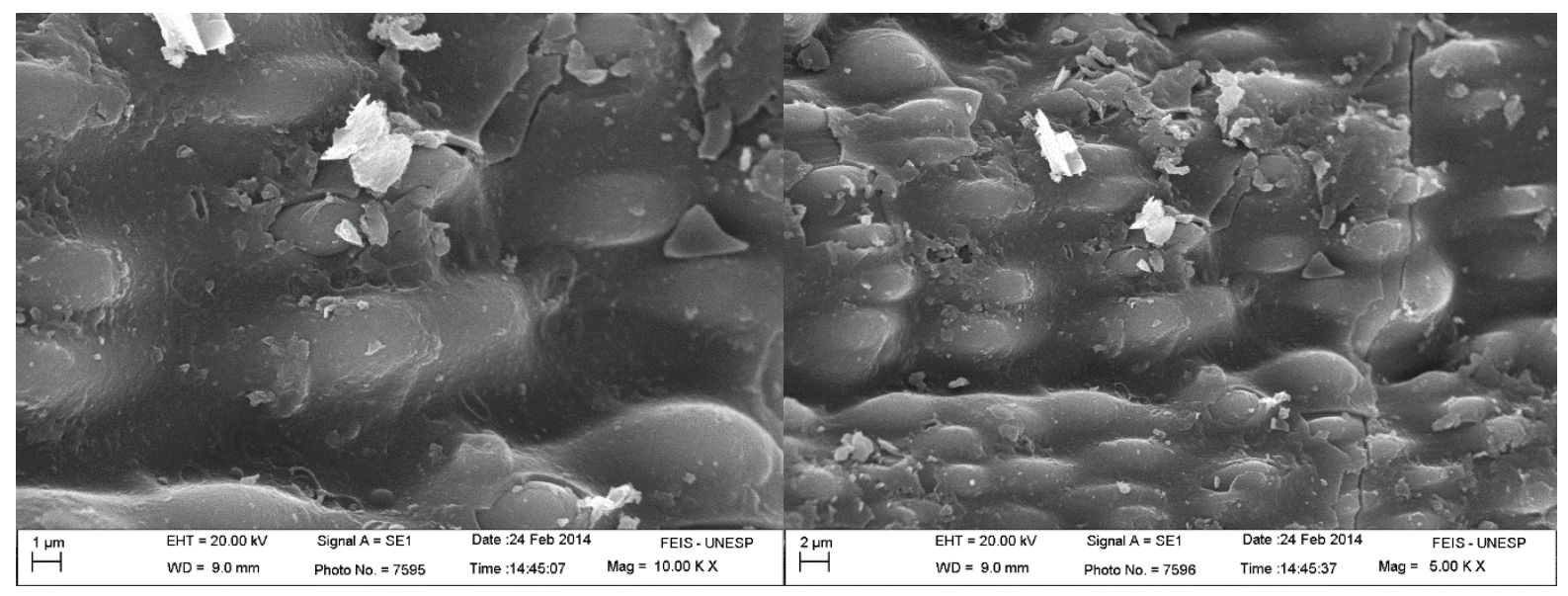

Figure 10. MEV of B2 horsetail sample

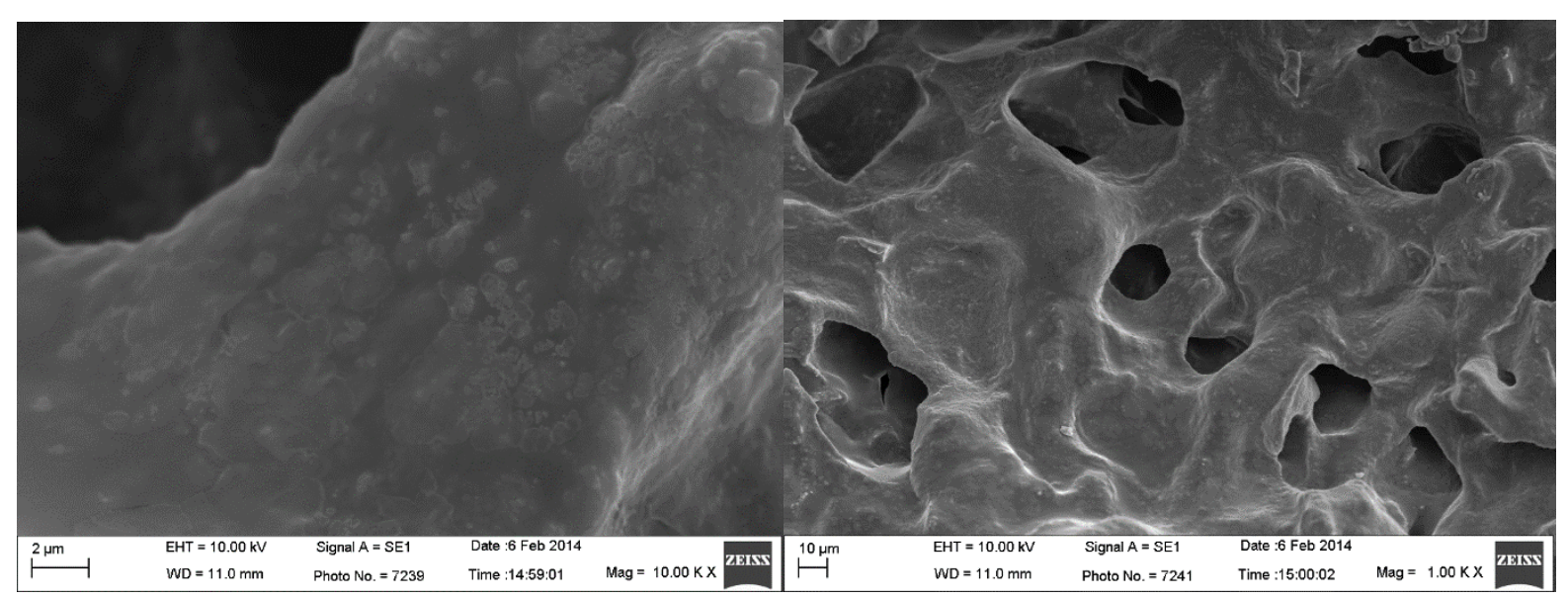

Figure 11. MEV of M horsetail sample 


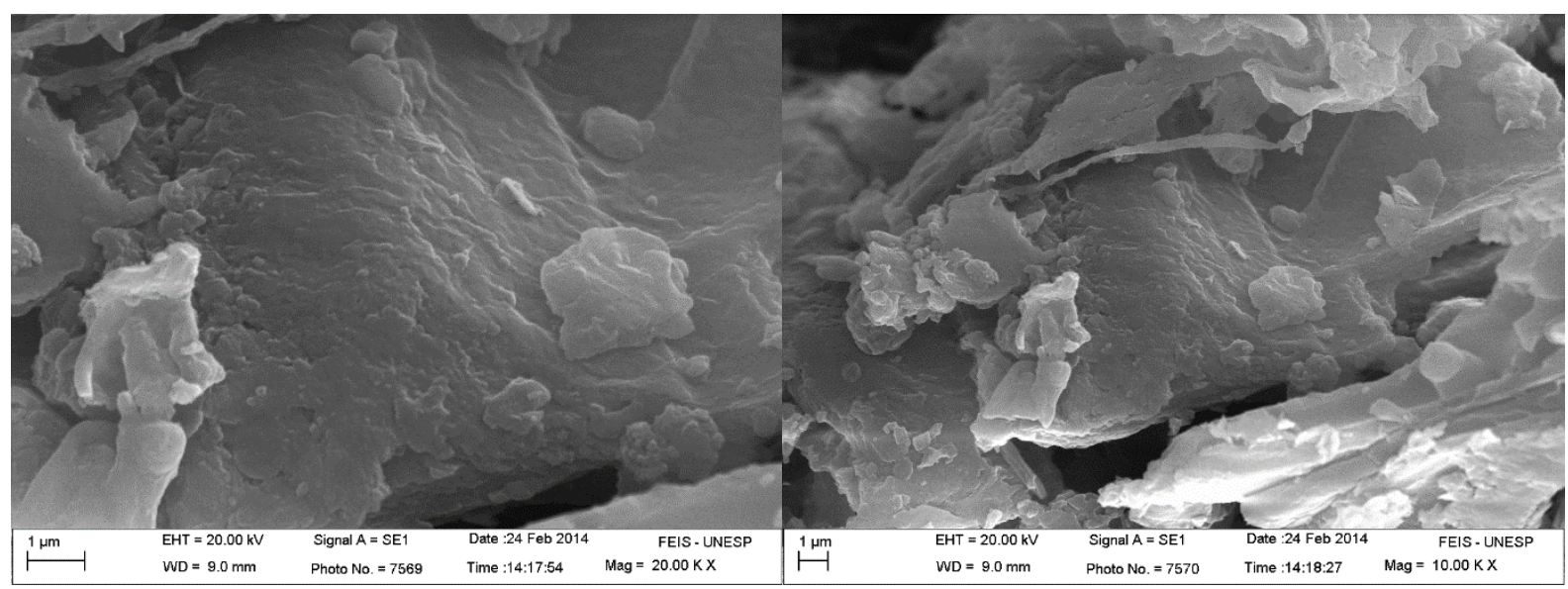

Figure 12. MEV of M1 horsetail sample

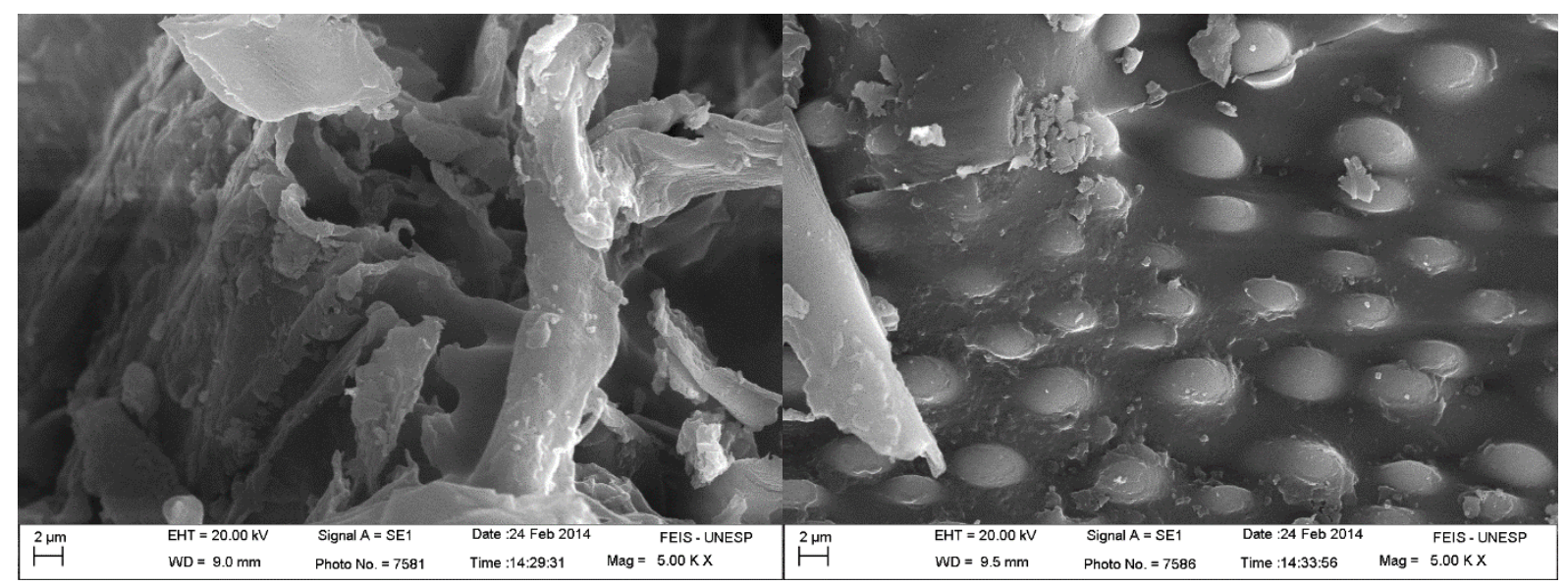

Figure 13. MEV of M2 horsetail sample

The solid phase (biomass) obtained after the extraction of the organic and inorganic components was applied in the metals adsorption process.

In the time study (adsorption equilibrium), adsorption curves were obtained by correlating $\mathrm{Nf}$ (number of moles of adsorbed metal ions) with time (minutes) and then the time required for the maximum adsorption of the metal ions was determined. In adsorption isotherms illustrated in Figure 14, it was found that the time at which the adsorption saturation of the $\mathrm{Cu}^{2+}$ metal ion was initiated for both horsetails was about 65 minutes, but a time of 70 minutes was used for the concentration study in order to have a safe margin of equilibrium time. 


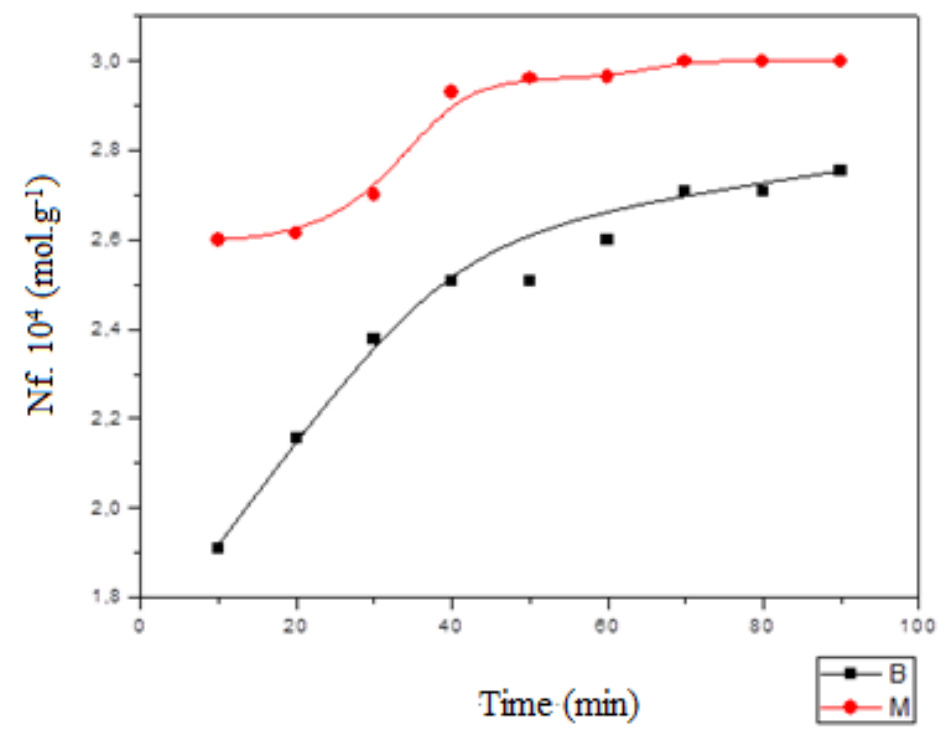

Figure 14. Kinetic curves of $\mathrm{B}$ and $\mathrm{M}$ horsetails

The adsorption capacity is expressed in adsorption isotherms, which relates $\mathrm{Nf}$ to the concentration of metal ion (Cs). As shown in Figure 15, the beginning of active sites saturation for the material occurred from the concentration of $12 \times 10^{-4} \mathrm{~mol} \mathrm{~L}^{-1}$ of the metal for $\mathrm{M}$ horsetail and $13.7 \times 10^{-4} \mathrm{~mol} \mathrm{~L}^{-1}$ for B horsetail. The maximum adsorption capacity $\mathrm{Nf}^{\text {max }}$ of $\mathrm{M}$ horsetail was $4.4 \times 10^{-4} \mathrm{~mol} \mathrm{~g}^{-1}$ and for B horsetail was $2.6 \times 10^{-4} \mathrm{~mol} \mathrm{~g}^{-1}$. It was observed that $\mathrm{Nf}$ increases with $\mathrm{Cs}$ and it was found that the horsetail with the highest adsorption capacity was the manipulated one in pharmacy (M). The $\mathrm{Nf}$ values for each horsetail are expressed in tables 2 and 3 for mackerel B and M respectively.

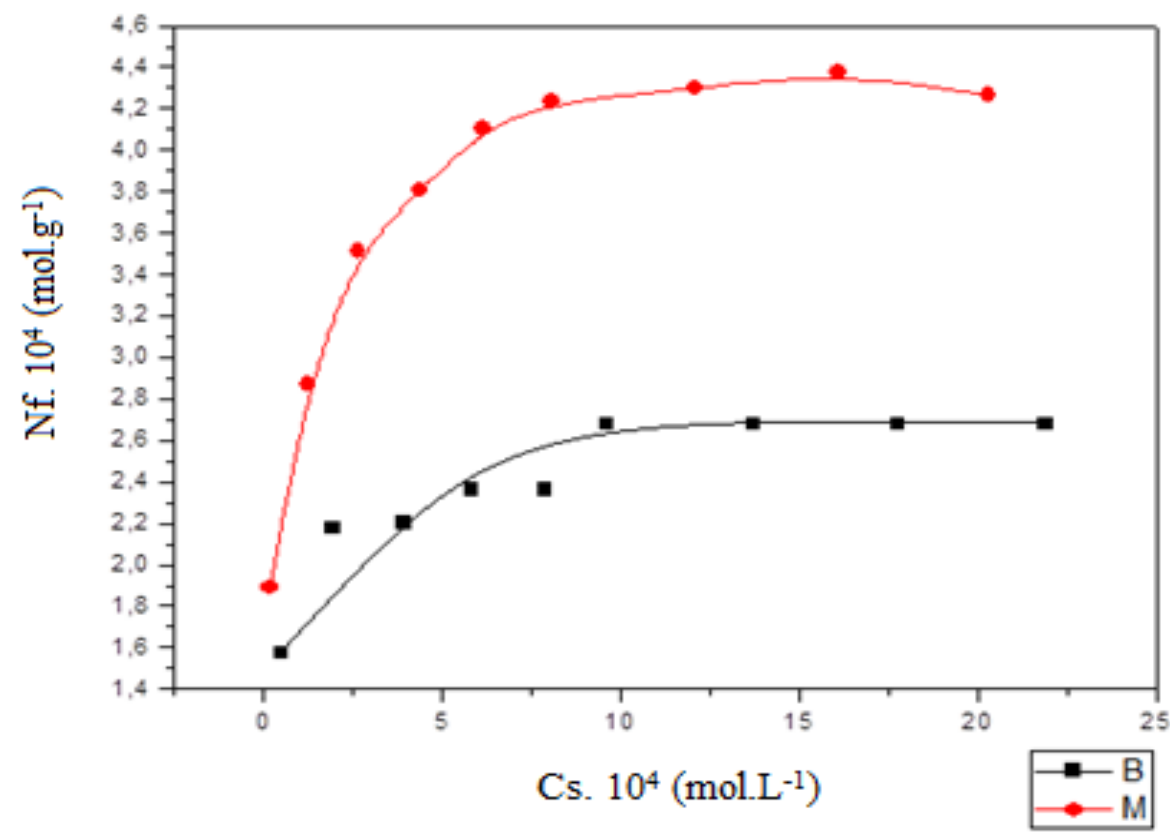

Figure 15. Adsorption isotherms of B and M horsetail 
Table 2. Nf values for horsetail B

\begin{tabular}{cc}
\hline $\mathrm{Cs} \cdot 10^{4}\left(\mathrm{~mol} . \mathrm{L}^{-1}\right)$ & $\mathrm{Nf} .10^{4}\left(\mathrm{~mol} \cdot \mathrm{g}^{-1}\right)$ \\
\hline 0,472 & 1,576 \\
1,920 & 2,174 \\
3,936 & 2,204 \\
5,826 & 2,362 \\
7,874 & 2,362 \\
9,606 & 2,676 \\
13,700 & 2,676 \\
17,800 & 2,680 \\
21,880 & 2,680 \\
\hline
\end{tabular}

Table 3. Nf values for horsetail M

\begin{tabular}{cc}
\hline Cs.10 $\left(\mathrm{mol}_{\mathrm{L}}^{-1}\right)$ & $\mathrm{Nf} .10^{4}\left(\mathrm{~mol} . \mathrm{g}^{-1}\right)$ \\
\hline 0,157 & 1,889 \\
1,225 & 2,869 \\
2,630 & 3,510 \\
4,378 & 3,810 \\
6,126 & 4,102 \\
8,048 & 4,234 \\
12,078 & 4,298 \\
16,094 & 4,376 \\
20,300 & 4,264 \\
\hline
\end{tabular}

\section{Conclusion}

Through electronic and vibrational spectroscopy techniques, it was observed that the extract of the Equisetum arvense sample in aqueous medium, after lyophilization presented some organic constituents as compounds of flavonoids family, probably responsible for phytotherapeutic properties. By FTIR, MEV and EDX it is possible to prove the existence of soluble compounds based on $\mathrm{Si}$, besides other elements (C, O, $\mathrm{Ca}, \mathrm{Mg}, \mathrm{Na}, \mathrm{P}, \mathrm{S}, \mathrm{Cl}$ and $\mathrm{K}$ ). It was verified that part of the organic compounds was found in the solid phase (extraction waste) and these present chelating properties with expressive adsorption capacity of copper ions in aqueous medium.

\section{Acknowledgments}

The authors are grateful to the Coordenação de Aperfeiçoamento de Nível Superior (CAPES) and the Conselho Nacional de Desenvolvimento Científico e Tecnológico (CNPq) for the financial support. Besides to University Paulista State for equipment's and the facilities, where this evaluation has been carried out.

\section{References}

Cechinel-Filho, V., Santos, A. R. S., Campos, R. O. P., Miguel, O. G., Yunes, R. A., Ferrari, F., ... Calixto, J. B. (1996). Chemical and pharmacological studies of Phyllanthus caroliniensis. J. Pharm. Pharmacol., 48, 1231-1236. https://doi.org/10.1111/j.2042-7158.1996.tb03928.x

Cramer, L., Ernst, L., Lubienski, M., Papke, U., Schiebel, H., Jerz, G., \& Beuerle, T. (2015). Structural and quantitative analysis of Equisetum alkaloids. Phytochemistry, 116, 269-282. https://doi.org/10.1016/j.phytochem.2015.03.003

Da Silveira, T. F. S., Fernandes, D. S., Barbosa, P. F. P., \& Do Carmo, D. R. (2018). Preparation and use of a Grafted Silica with Imidazole Groups for Cadmium Sorption and Subsequent Voltammetric Detection of Ascorbic Acid. Silicon, 10, 635-643. https://doi.org/10.1007/s12633-016-9506-9

Datta, S., Christena, L. R., \& Rajaram, Y. R. S. (2013). Enzyme immobilization: an overview on techniques and support materials. Biotechnology, 3(1), 1-9. https://doi.org/10.1007/s13205-012-0071-7 
Des Marais, D. L., Smith, A. R., Britton, D. M., \& Pryer, K. M. (2003). Phylogenetic relationships and evolution of extant horsetails, Equisetum, based on chloroplast DNA sequence data ( $\mathrm{rbcL}$ and trnL-F). International Journal of Plant Science, 164, 737-751. https://doi.org/10.1086/376817

Di Giorgio, C., Boyer, L., De Meo, M., Laurant, C., Elias, R., \& Ollivier, E. (2015). In vitro and in vivo antimutagenic effects of DIG, an herbal preparation of Berberis vulgaris, Taraxacum officinale and Arctium lappa, against mitomycin C. Journal of Natural Medicines, 69, 267-277. https://doi.org/10.1007/s11418-015-0886-8

Dos Santos, J. G., Blanco, M. M., Do Monte, F. H. M., Russi, M., Lanziotti, V. M. N. B., Leal, L. K. A. M., \& Cunha, G. M. (2005). Sedative and anticonvulsant effects of hydroalcoholic extract of Equisetum arvense. Fitoterapia, 76, 508-513. https://doi.org/10.1016/j.fitote.2005.04.017

Ferraz, M. P., Pereira, A. C., Lopes, M. A., \& Fernandes, M. H. (2008). Equisetum Arvense: avaliação das possibilidades de aplicação na regeneração óssea. Revista da Faculdade de Ciências da Saúde, 136-145.

Francescato, L. N., Debenedetti, S. L., Schwanz, T. G., Bassani, V. L., \& Henriques, A. T. (2013). Indetification of phenolic compounds in Equisetum giganteum by LC-ISI-MS/MS and a new approach to total flavonoid quantification. Talanta, 105, 192-203. https://doi.org/10.1016/j.talanta.2012.11.072

Franco, I. J., \& Fontana, V. L. (1997). Ervas \& Plantas. A medicina dos simples. Chapecó - SC: Imprimax.

Gürbüz, I., \& Yesilada, E. (2008). In vivo anti-ulcerogenic activity of Equisetum telmateia Ehrh. extracts used in Turkish folk medicine. Turkish Journal of Biology, 32, 259-263.

Hodson, M., White, P., Mead, A., \& Broadley, M. (2005). Phylogenetic variation in the silicon composition of plants. Annals Botany, 96, 1027-1046. https://doi.org/10.1093/aob/mci255

Holzhuter, G., Narayanan, K., \& Gerber, T. (2003) Structure of silica in Equisetum arvense. Analytical Bioanalytical Chemistry, 376, 512-517. https://doi.org/10.1007/s00216-003-1905-2

Husby, C. (2013). Biology and Functional Ecology of Equisetum with Emphasis on the Giant Horsetails. The Botanical Review, 79, 147-177. https://doi.org/10.1007/s12229-012-9113-4

Lopes, W. A., \& Fascio, M. (2004). Flow chart for infrared spectra interpretation of organic compounds. Química Nova, 27(4), 670-673. https://doi.org/10.1590/S0100-40422004000400025

Ma, J. F., Tamai, K., Yamaji, N., Mitani, N., Konishi, S., Katsuhara, M., ... Yano, M. (2006). A silicon transporter in rice. Nature,440, 688-691. https://doi.org/10.1038/nature04590

Mimica-Dukic, N., Simin, N., Cvejic, J., Jovin, E., Orcic, D., \& Bozin, H. (2008). Phenolic Compounds in Field Horsetail (Equisetum arvense L.) as Natural Antioxidants. Molecules, 13, 1455-1464. https://doi.org/10.3390/molecules13071455

Mitani, N., \& Ma, J. F. (2005). Uptake system of silicon in different plant species. Journal of Experimental. Botany, 56, 1255-1261. https://doi.org/ 10.1093/jxb/eri121

Sola-Rabada, A., Rinck, J., Belton, D. J., Powell, A. K., \& Perry, C. C. (2016). Isolation of a wide range of minerals from a thermally treated plant: Equisetum arvense, a Mare's tale. Journal of Biological Inorganic Chemistry, 21, 101-112. https://doi.org/10.1007/s00775-015-1320-0

Vivancos, J., Deshmukh, R., Grégoire, C., Rémus-Borel W., Belzile, F., \& Bélanger, R. R. (2016). Identification and characterization of silicon efflux transporters in horsetail (Equisetum arvense). Journal of Plant Physiology, 200, 82-89. https://doi.org/10.1016/j.jplph.2016.06.011

\section{Copyrights}

Copyright for this article is retained by the author(s), with first publication rights granted to the journal.

This is an open-access article distributed under the terms and conditions of the Creative Commons Attribution license (http://creativecommons.org/licenses/by/4.0/). 